DOI: https://doi.org/10.36910/6775-2524-0560-2021-42-01

УДК: $004.942+004.383 .3$

${ }^{1}$ Наливайчук Микола Васильович, ст. викладач

https://orcid.org/0000-0002-8942-9844

${ }^{2}$ Шолохов Олексій Вікторович, начальник групи

https://orcid.org/0000-0002-8676-3724

${ }^{1}$ Національний технічний університет України "Київський політехнічний інститут імені Ігоря

Сікорського".

${ }^{2}$ Казенне підприємство спеціального приладобудування «Арсенал» ДКАУ.

\title{
МОДЕЛЮВАННЯ ТА АЛГОРИТМИ ОБРОБКИ ІНФОРМАЦІЇ СУПУТНИКОВОГО АДАПТИВНОГО НАДПРОВІДНОГО ГРАВІМЕТРА
}

Наливайчук М. В., Шолохов О. В. Моделювання та алгоритми обробки інформації супутникового адаптивного надпровідного гравіметра. Обгрунтовані принципи створення перспективного супутникового гравіметра, придатного для отримання оперативної інформації щодо гравітаційного поля. Розроблено математичні моделі динаміки та стійкості керованого надпровідного підвісу. Побудовано чисельні алгоритми оцінювання величини гравітаційного збурення, що впливає на левітаційне пробне тіло. Обгрунтовано технологію створення макету супутникового гравіметра на основі високотемпературних надпровідних наноплівок.

Ключові слова: вимірювально-обчислювальна система, алгоритм, пробне тіло, динамічна модель, гравіметр, моделювання, оптимізація, керуючий вплив, адаптивна фільтрація, мікропроцесор.

Наливайчук Н. В., Шолохов А. В. Моделирование и алгоритмы обработки информации спутникового адаптивного сверхпроводящих гравиметров. Обоснованы принципы создания перспективного спутникового гравиметра, пригодного для получения оперативной информации о гравитационном поле. Разработаны математические модели динамики и устойчивости управляемого сверхпроводящего подвеса. Построены численные алгоритмы оценивания величины гравитационного возмущения, влияющего на левитирующее пробное тело. Обоснована технология создания макета спутникового гравиметра на основе высокотемпературных сверхпроводящих нанопленок.

Ключевые слова: измерительно-вычислительная система, алгоритм, пробное тело, динамическая модель, гравиметр, моделирование, оптимизация, управляющее воздействие, адаптивная фильтрация, микропроцессор.

Nalyvaichuk M. V., Sholokhov O.V. Modeling and Information processing algorithms of satellite adaptive superconducting gravimeter. Principles of satellite gravimeter creation to obtain an information about gravitational field are considered. The mathematical model of the dynamic and stability of controlled superconducting suspension has been developed. Numerical algorithms for gravitational perturbation estimation acting on levitated probe have been proposed. The technology of satellite gravimeter creation based on high-temperature superconducting nanofilms has been proposed.

Keywords: measuring-computing system, algorithm, probe, dynamic model, gravimeter, modeling, optimization, control, adaptive filtering, microprocessor.

Постановка наукової проблеми. У галузі гравіметрії однією з актуальних проблем є підвищення точності супутникового гравіметра. Серед найкращих стаціонарних наземних гравіметрів точність складає $10^{-8} \mathrm{~g}$, для гравіметрів морського базування $-10^{-7} \mathrm{~g}$, а для авіаційного $-10^{-6} \mathrm{~g}$. При сучасних темпах розвитку багатьох галузей прикладних наук (космічні дослідження, геологія, навігація, моніторинг природних ресурсів на основі аналізу гравітаційних аномалій, вивчення глобальних геодинамічних процесів, гравітаційного поля і форми Землі, руху полюсів Землі тощо) зазначена точність $є$ недостатньою. Підвищення точності гравіметра сприятиме збільшенню точності спостережень визначення місця розташування та орієнтації для довготривалих авіа польотів і плавань підводних апаратів, тому необхідно знати гравітаційне поле Землі, а також його аномалії. Детальна інформація про гравітаційне поле Землі необхідна також багатьом галузям прикладних наук (космічні дослідження, геологія, навігація, наука про форму Землі). Дійсно, точне і швидке детектування геодинамічних процесів може дозволити отримати дані щодо зародження і розвитку критичних локальних і глобальних екологічних станів. Іншою практичною проблемою $є$ потреба отримання інформації щодо нерозвіданих корисних копалин Землі.

Тому, для розв'язання даної проблеми, пропонуються різні макети надпровідних гравіметрів, що відрізняються способом неконтактного підвішування чутливої маси гравіметра, використанням електричних або магнітних сил, методами вимірювання зміщень чутливої маси гравіметра (системи оптичної реєстрації, Джозефсонівські ефекти як основа вимірювань тощо), а також комп'ютерними методами оброблення сигналів $[5,11]$. Стрибок у вдосконаленні гравіметрів став можливим завдяки фінансуванню розробок надпровідних гравіметрів. У роботі [5] описується в деталях надпровідний гравіметр, базова конструкція якого залишається незмінною протягом більше 30-ти років 3 моменту першої публікації в [11]. Вільний стан (левітація) чутливої маси цього гравіметра досягається на основі ефекту Браунбека-Мейснера $[10,11]$. 
Аналіз досліджень. Дослідження підвищення точності супутникового надпровідного гравіметра 3 керованим магнітним підвісом на основі наноплівок та процесорного мікромодуля, придатного для отримання оперативної інформації щодо гравітаційного поля, раніше не проводились. Тому, оскільки апаратне, алгоритмічне і математичне забезпечення такого гравіметра є невід'ємною частиною, яка впливає на його точність, воно потребує подальшої уваги.

Виклад основного матеріалу й обгрунтування отриманих результатів дослідження. Метою даної статті $\epsilon$ обгрунтування та розроблення наукових основ та пропозицій щодо створення перспективних супутникових гравіметрів, що включають принципово новий керований магнітний підвіс (чутливий елемент) на основі наноплівок з використанням явища керованої магнітної левітації та процесорного мікромодуля; обгрунтування технології розроблення функціональних вузлів на основі високотемпературних надпровідних наноплівок для створення малогабаритного супутникового гравіметра.

Поставлена мета обумовила розв'язання наступних задач:

- необхідно розробити математичну модель динаміки та стійкості керованого надпровідного підвісу;

- запропонувати алгоритми ідентифікації та оцінювання;

- побудувати чисельні алгоритми оцінювання величини гравітаційного збурення, що впливає на левітаційне пробне тіло;

- провести аналіз впливу різних чинників на жорсткість підвісу, серед яких, зокрема - наявність додаткової феромагнітної маси на вільній пробній масі, вплив пасивного фільтру сигналів на точність вимірювань;

Математична модель динаміки та стійкості пробного тіла. Однією з актуальних задач механіки вільного тіла в магнітному полі є завдання складання та аналізу рівнянь динаміки вільного тіла в полі ідеально провідних струмових контурів. Це обумовлено можливістю використовуванню ефектів діамагнітного відштовхування $[10,11]$ та мінімуму магнітної потенційної енергії [2, 11], що дозволяють стабілізувати рівновагу вільного тіла [11]. В [2] обгрунтовано ефект мінімуму магнітної енергії і стійкості рівноваги вільного ідеально провідного струмового кільця, співвісного в положенні рівноваги до нерухомого ідеально провідного струмового кільця,

Проведено дослідження рівняння руху і стійкості при наявності не одного, а двох нерухомих ідеально провідних струмових кілець, що представляють собою консервативну потенційну систему. Для складання рівнянь динаміки використовується метод Лагранжа, який в $[2,4]$ розвинений, стосовно електромеханічних перетворювачів енергії. Виберемо в якості кінетичної енергії енергію магнітного поля. Нехай механічними координатами вільного ідеально провідного кільця $є$ циліндричні координати його центру маси $\rho, \alpha, \xi$ і кути Ейлера $\phi, \psi, \theta$, які визначають орієнтацію кільця щодо тригранника $O \xi \eta \zeta$ (Рис. 3). Початок тригранника $O \xi \eta \zeta$ поміщено в центрі верхнього нерухомого ідеально провідного кільця, а вісь $O \zeta$ співпадає з спільною віссю двох нерухомих ідеально провідних кілець.



Рис. 1. Орієнтація кільця відносно тригранника $O \xi \eta \zeta$

3 метою вивчення властивостей робочого макету гравіметра були проведені експериментальні дослідження динамічних характеристик магнітного підвісу вільної пробної маси робочого макета гравіметра (спільно з групою Інституту фізики НАНУ), а також доопрацьовано чутливий елемент магнітного підвісу.

Система рівнянь для змінних стану $\mathrm{y}_{1}, \ldots, \mathrm{y}_{6} \mathrm{i}$ функціонал $\mathrm{z}_{1}$ описують відображеня $\mathrm{y}_{1} \rightarrow \mathrm{z}_{1}$ інтерферометра, що допускає лінійне представлення (див. [5]). Шляхом введення функції $\mathrm{z}=\alpha \mathrm{y}_{1}+\beta \mathrm{y}_{2}$, де $\beta$ - константа, i прирівнюючи $\alpha_{1 j}=0, j=2, \ldots, 5$, одержуємо білінійну систему: 


$$
\begin{gathered}
{\left[\begin{array}{l}
\dot{y}_{1} \\
\dot{y}_{2}
\end{array}\right]=\left[\begin{array}{cc}
0 & 1 \\
a_{1} & 0
\end{array}\right]\left[\begin{array}{l}
y_{1} \\
y_{2}
\end{array}\right]+\left[\begin{array}{c}
0 \\
a_{2}+a_{3} y_{1}
\end{array}\right] u_{1}(t)+\left[\begin{array}{c}
0 \\
a_{5}+a_{4} y_{1}
\end{array}\right] u_{1}^{2}(t)\left[\begin{array}{c}
0 \\
a_{6}
\end{array}\right] u_{3}(t)+\left[\begin{array}{c}
0 \\
a_{7}
\end{array}\right]} \\
\boldsymbol{z}=\boldsymbol{\alpha} \boldsymbol{y}_{\mathbf{1}}+\boldsymbol{\beta} \boldsymbol{y}_{2},
\end{gathered}
$$

Тут $a_{1}=a_{11}, a_{2}=a_{17}, a_{3}=a_{18}, a_{4}=a_{110}, a_{5}=a_{19}, a_{6}=a_{16}, a_{7}=a_{111}$. Нехай $u_{3}(t)=$ $0, u_{4}(t)=0$. Отримаємо умови асимптотичної стійкості білінійної системи із лінійної системи вимірювання, умови існування якої приведені в $[2,7]$. Шляхом лінеаризації системи (1) в околі точки $y_{1}=0, y_{2}=0$ стійкої рівноваги пробного тіла при $u_{1}(t)=0$, одержимо (3) і (4):

$$
\begin{aligned}
& {\left[\begin{array}{l}
\dot{x_{1}} \\
\dot{x_{2}}
\end{array}\right]=\left[\begin{array}{ll}
0 & 1 \\
a_{1} & 0
\end{array}\right]\left[\begin{array}{l}
x_{1} \\
x_{2}
\end{array}\right]+\left[\begin{array}{c}
0 \\
a_{2}
\end{array}\right] u_{1}(t),} \\
& z=[\alpha \beta]\left[\begin{array}{ll}
x_{1} & x_{2}
\end{array}\right]^{T},
\end{aligned}
$$

де $z$ - вихідний сигнал лазерного інтерферометра, $\alpha, \beta$ - коефіцієнти підсилення, $x_{1}-$ стан системи, $x_{2}-$ прискорення пробного тіла, $t \in[0, T], u_{1}=t$ - зворотній зв'язок.

Систему (3), (4) запишемо в більш загальному вигляді (5):

$$
\dot{x}=A x+B u_{1}(t), z=C x
$$

Визначимо керування $[6,9,10]$ :

$$
u_{1}(t)=K(z), K(0)=0,
$$

яке забезпечує асимптотичну стійкість незбуреного руху $x=0$.

Із керованості лінійної системи

$$
\dot{x}=A x+B u_{1}(t)
$$

випливає стабілізованість білінійної системи (1) лінійним керуванням

$$
u_{1}(t)=F .
$$

Нехай $\Theta(\lambda)=a_{1} \lambda^{2}+a_{2} \lambda+a_{3}-$ будь який ненормований многочлен, всі корені якого мають від'ємні дійсні частини. Знайдемо таку матрицю $K$, щоб корені характеристичного полінома матриці $A+B K C$ співпадали з коренями полінома $\Theta(\lambda)$.

В силу керованості системи (7) існує матриця $F=\left\|f_{j}\right\|,(j=1,2)$ така, що $A+B K C$ має заданий спектр. Отже, існування шуканої матриці $K$ еквівалентне існуванню розв'язку рівняння

$$
K C=F .
$$

Введемо наступні позначення:

$$
C_{1}=\alpha, C_{2}=\beta, \mathrm{E}_{1}=\left[\begin{array}{ll}
1 & 0
\end{array}\right]^{T}, E_{2}=\left[\begin{array}{ll}
0 & 1
\end{array}\right] .
$$

Для існування матриці $K$, яка задовольняє рівнянню (8), необхідно і достатньо виконання умови

в якій враховується (4),

$$
F Q=0, Q=E_{2}-E_{1} C_{1}^{-1} C_{2}
$$

$$
Q=\left[\begin{array}{c}
-\alpha^{-1} \beta \\
1
\end{array}\right] .
$$

Якщо елементи матриці (11) розглядати як координати вектора $q$ в двомірному просторі, то умова (10) означає, що вектор $s=\left\{f_{j}\right\}, j=1,2$, повинен бути колінеарним вектору $q=\left\{1, \quad \alpha^{-1} \beta\right\}$. Отже, при фіксованій орієнтації осі чутливості квантового інтерферометра рівняння (9) задовольняє одно параметричній множині матриць $F$ вигляду

$$
F=\left[f_{1} \alpha^{-1} \quad \beta f\right] .
$$

Щоб характеристичний поліном матриці $A+B F$ співпадав 3 заданим поліномом $\Theta(\lambda)$, необхідно, щоб виконувалися умови $f_{1}=-\left(a_{3}+a_{1}\right) a_{2}^{-1}, a_{1}=1, a_{2}=-a_{2} \alpha^{-1} \beta f_{1}$. Таким чином, при $a_{1}=1, a_{2} \neq 0, \alpha \neq 0$, матриця $K=F E_{1} C_{1}^{-1}$ зворотного зв'язку по виходу визначається виразом

$$
K=\left[f_{1} \alpha^{-1}\right]
$$

і керування $u_{1}(t)=K z=f_{1} \alpha^{-1} z$ забезпечує асимптотичну стійкість положення рівноваги (1) в деякій області $H$ зміни $x$. 
Показано, що ідеї та методи теорії керування можуть бути використані для стабілізації левітуючого пробного тіла.

Ідентифікація динаміки пробного тіла. Запишемо систему (1), де $\dot{y}_{1}=y_{2}, u_{2}=u_{1}^{2}, a_{6}=$ $0, a_{7}=0, u_{3}=0$, у наступному вигляді:

$$
\ddot{y}_{1}=\left(a_{1}+a_{3} u_{1}+a_{4} u_{2}\right) y_{1}+a_{2} u_{1}+a_{5} u_{2},
$$

Уведемо заміну: $a_{1}+a_{3} u_{1}+a_{4} u_{2}=g, a_{2} u_{1}+a_{5} u_{2}=h$, тоді рівняння (14) матиме наступний вигляд:

$$
\ddot{y_{1}}=g y_{1}+h .
$$

Для знаходження загального розв'язку рівняння (15), уведемо нову функцію $P f(y)$, за умови $P f(y)=\dot{y}_{1}$. Тоді запишемо $\ddot{y}_{1}=\frac{\mathrm{d}}{\mathrm{d} t} \dot{y}_{1}=\frac{\mathrm{d} P f}{\mathrm{~d} t}=\frac{\mathrm{d} P f}{\mathrm{~d} y_{1}} \frac{\mathrm{d} y_{1}}{\mathrm{~d} t}=\frac{\mathrm{d} P f}{\mathrm{~d} y_{1}} P f, \frac{\mathrm{d} P f}{\mathrm{~d} y_{1}} P f=g y_{1}+h, \int P f * \mathrm{~d} P f=$ $\int\left(g y_{1}+h\right) * \mathrm{~d} y_{1}$. Розв'язок останнього рівняння наведений формулою (16).

$$
\text { Pf }=y_{2}= \pm \sqrt{\frac{1}{g}\left(g y_{1}+h\right)^{2}+C_{1}} \text {. }
$$

Підставивши $\dot{y}_{1}=y_{2}$ в (16), отримаємо нове диференційне рівняння, загальний розв'язок якого представлений формулами (17) i (18).

де $C_{1}, C_{2}$ - константи інтегрування.

$$
\begin{aligned}
& y_{1}^{1}=\frac{\mathrm{e}^{\sqrt{\mathrm{g}}\left(\mathrm{C}_{2} \pm \mathrm{t}\right)}}{2 g}-\frac{C_{1}}{2 \mathrm{e}^{\sqrt{\mathrm{g}}\left(\mathrm{C}_{2} \pm \mathrm{t}\right)}}-\frac{h}{g}, \\
& y_{1}^{2}=\frac{C_{1}}{2 \mathrm{e}^{\sqrt{\mathrm{g}\left(C_{2} \pm \mathrm{t}\right)}}}-\frac{\mathrm{e}^{\sqrt{\mathrm{g}}\left(\mathrm{C}_{2} \pm \mathrm{t}\right)}}{2 g}-\frac{h}{g},
\end{aligned}
$$

Стан системи у початковий момент часу невідомий. Відомими $є$ множини $z, u_{1}, u_{2}$ у кожний момент часу $t, \operatorname{Card}(z)=\operatorname{Card}\left(u_{1}\right)=\operatorname{Card}\left(u_{2}\right)=N$. Для параметричної ідентифікації (14) і (2) пропонується наступний алгоритм.

Нехай кількість станів системи $p=L$, де $L-$ максимальна ступінь виразу, який зобразимо у наступному вигляді:

де $q=\overline{1 . . p}$.

$$
\hat{y}_{q}=u_{1}^{q}+u_{2}^{q}
$$

Тепер нехай $\hat{z}=a \hat{y}_{1}+b \hat{y}_{2}$, а задача (20) на знаходження параметрів $a, b$ не $\epsilon$ перепараметризованою:

$$
\sum_{i=1}^{N}\left(z_{i}-\widehat{z_{l}}\right)^{2} \rightarrow \min .
$$

Для знаходження параметрів (14), запишемо задачу оптимізації (21):

$$
S_{j}=\sum_{i=1}^{N}\left(y_{1 i}^{j}-\widehat{y_{1 l}}\right)^{2} \rightarrow \min , j=\overline{1 . .2}
$$

Програмна реалізація та апробація алгоритму виконані в середовищі MatLab (рис. 2).

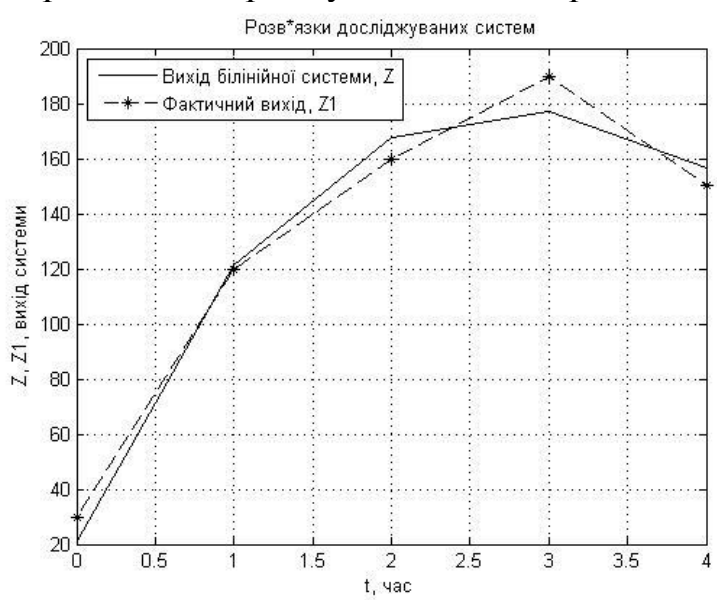

Рис. 2. Динаміка фактичного та теоретичного виходів системи

Запропонований алгоритм дозволяє подолати проблему перепараметризованості, яка $є$ актуальною при ідентифікації білінійних систем (за умови, що відомий загальний розв'язок) і $є$ перешкодою при застосуванні класичного підходу ідентифікації [30].

Еліпсоїдальне оцінювання вектору стану. Для розв'язування задачі оцінювання вектору стану системи (3) пропонується алгоритм еліпсоїдального оцінювання, який полягає у наступному (17):

$$
\dot{x}=A x+B\left(u_{1}+\xi\right)
$$


Припустимо, що процес стаціонарний. Для зручності перепишемо (4) у компактному вигляді 3 урахуванням невизначеності (18):

$$
z=C x+v
$$

$|\xi| \leq d$ и $|v| \leq c$ - обмежені за абсолютною величиною збурювання й шум, відповідно.

Таким чином, оцінка векторної величини $x$ у момент часу $t$ являс собою деяку обмежену множину, яку зручно апроксимувати множиною канонічної форми, наприклад, еліпсом $E$ [23]. Оскільки оброблення спостережень і побудова множинної оцінки стану (17) здійснюється дискретно, зручно перейти до дискретного подання процесу (17), використавши фіксатор нульового порядку [24, 25]. Зазначене перетворення зручно виконати засобами MatLab [26] і далі використовувати в комп'ютерному моделюванні. У цьому випадку (17), (18) перепишемо в нових позначеннях (19) і (20):

$$
\begin{gathered}
x_{k+1}=A_{k} x_{k}+B_{k}\left(u_{1, k}+\xi_{k}\right), \\
z_{k}=C x_{k}+v_{k},
\end{gathered}
$$

де нижній індекс $k \in N$ - номер спостереження за процесом у дискретному поданні; матриці $A_{k}, B_{k}$ отримані в результаті перетворення безперервного процесу (17) у його дискретне подання. Використавши роботу [27], будуємо еліпсоїдальну множину досяжності [23], а потім, скориставшись алгоритмом [28], одержуємо еліпсоїдальну оцінку вектора можливих станів процесу (17). На напівінтервалі $[k, k+1]$ вважаємо керування $u_{1, k}$, збурювання $\xi_{k}$ й шум $v_{k}$ постійними.

$$
\begin{gathered}
\tilde{x}_{k+1}=A_{k} \tilde{x}_{k}+B_{k} u_{1, k} \mid \tilde{x}_{1}=\bar{x}, \\
\widetilde{H}_{k+1}=\left(1+\delta_{k}\right) A_{k} \widetilde{H}_{k} A_{k}^{T}+\left(1+\delta_{k}^{-1}\right) B_{k} B_{k}^{T} d^{2} \mid \widetilde{H}_{1}=\bar{H}, \\
\tilde{E}_{k+1}=\left\{x_{k+1}:\left(x_{k+1}-\tilde{x}_{k+1}\right)^{T} \widetilde{H}_{k+1}^{-1}\left(x_{k+1}-\tilde{x}_{k+1} \leq 1\right\}\right.
\end{gathered}
$$

Тут $\tilde{x}_{k+1}$ - прогнозне значення вектора станів процесу; $\widetilde{H}_{k+1}$ - матриця еліпса $\widetilde{E}_{k+1}$ множини досяжності процесу (19). Значення $\bar{x}$ й $\bar{H}$ задаються приблизно. $\delta_{k}-$ єдиний позитивний корінь рівняння [27]

$$
n \delta_{k}^{2}+k_{k}^{2}(n-1) \delta_{k}-k_{k}^{2}=0, k_{k}^{2}=B_{k}^{T} \widetilde{H}_{k}^{-1} B_{k} d^{2}
$$

У рівнянні (24) параметр $n=2$ - розмірність вектора $x_{k}$.

Обробивши виміри (20), одержимо оцінку множини можливих станів процесу (5):

$$
\begin{gathered}
\hat{x}_{k+1}=\tilde{x}_{k+1} \tau_{k+1} \frac{\widetilde{H}_{k+1} C^{T}}{e_{k+1}} \sigma_{k+1}, \\
\widehat{H}_{k+1}=\left(\widetilde{H}_{k+1}-\tau_{k+1} \frac{\widetilde{H}_{k+1} C^{T} C \widetilde{H}_{k+1}}{e_{k+1}^{2}}\right) \gamma_{k+1}^{2}, \\
\gamma_{k+1}^{2}=1+\tau_{k+1}\left(\frac{1}{1-\tau_{k+1}} \chi_{k+1}^{2}-\sigma_{k+1}^{2}\right), \\
\tau_{k+1} \leq \frac{1+n\left(\sigma_{k+1}^{1}-\chi_{k+1}^{2}\right)}{1+n \sigma_{k+1}^{2}}, 0 \leq \tau_{k+1}<1 .
\end{gathered}
$$

де $n=2$ - розмірність вектора $x_{k}, e_{k+1}^{2}=C \widetilde{H}_{k+1}, \sigma_{k+1}=\frac{\Delta_{k+1}}{e_{k+1}}, \Delta_{k+1}=z_{k+1}-C \tilde{x}_{k+1}, \chi_{k+1}^{2}=\frac{c^{2}}{e_{k+1}^{2}}$, $c$ - найбільше абсолютне значення шуму $v_{k}$.

У (21), (22) на $k+2$ кроці перевизначаємо: $\widetilde{x}_{k+1}=\widehat{x}_{k+1}, \widetilde{H}_{k+1}=\widehat{H}_{k+1}$,.

Керування $u_{1, k}$ задається законом (14) і визначається обраним критерієм: $\operatorname{det} \widehat{H}_{k+1} / \operatorname{det} \widehat{H}_{k} \leq 1$, $\operatorname{tr} \widehat{H}_{k+1} / \operatorname{tr} \widehat{H}_{k} \leq 1$ або відношенням інших матричних норм. 
Висновки та перспективи подальшого дослідження. Обгрунтовано принципи створення перспективного супутникового гравіметра, придатного для отримання оперативної інформації щодо гравітаційного поля. Розроблено математичну модель динаміки та стійкості керованого надпровідного підвісу.

Побудовано алгоритм ідентифікації динаміки пробного тіла та проведено еліпсоїдальне оцінювання вектору стану. Побудовано чисельні алгоритми оцінювання величини гравітаційного збурення, що впливає на левітуюче пробне тіло.

Розроблено технічні пропозиції щодо створення магнітного підвісу на високотемпературних наноплівках та здійснено наукове-технічне обгрунтування макету супутникового гравіметра на основі високотемпературних надпровідних наноплівок з використанням процесорного мікромодуля.

Обгрунтовано технологію створення макету супутникового гравіметра на основі високотемпературних надпровідних наноплівок.

Подальше дослідження пропонується проводити в напрямку використання останніх наукових розробки сучасних надпровідних матеріалів, що переходять в стан надпровідності при ще більш високих температурах і з яких можна створити чутливий елемент сенсора,

\section{Список бібліографічного опису}

1. Yatsenko V.A., Nalivaichuk N.V. Mathematical modeling and optimization of controlled superconducting sensors with magnetic levitation // Моделювання та дослідження стійкості динамічних систем: Збірник наукових праць міжнародна конференції DSMSI-2011. Київ, 2011. С. 146.

2. Yatsenko V.A. and Kryuchkov E.I. On the possibility of application of "Magnetic Potential Well" effect for creation of a graviinertial cryogenic device. Journal of Automation and Information Science, V. 34, 2003.-P. 106-119.

3. W.A. Prothero and J. M. Goodkind. A superconducting gravimeter. - Rev. Sci. Instr, № 2 , Vol. 39, № 9. 1968.- P. 1257 1261.

4. V.Yatsenko and P.Pardallos, Global optimization of cryogenic-optical sensor, in Sensors, Systems, and Next-Generation Satellites, K. W.H. Fujisada, J. Lirie, ed., Proc. SPIE 4550, гг. 433 - 441, 2001.

5. V. Yatsenko, M. Nalyvaichuk. Modeling and Optimization of Cryogenic-Optical Gravimeters // International Journal information theories \& applications. - 2012. - P. 232-240. Vol. 19. № 3.

6. V. Yatsenko, M. Nalyvaichuk. Cryogenic-Optical Gravimeter: Principles, Methods and Applications // Kharkov University Vestnik, Ser. Radiophysics and Electronics.-2011.- P. 107-113.

7. V. Yatsenko, M. Nalyvaichuk, V. Gnidenko, O. Kochkodan. Modeling of Superconducting Gravimeter for Futute Space Missions: Optimization. Control, and Estimation//2nd International Conference on memory of corresponding member of National Academy of Science of Ukraine V. S. Melnik, 4-6 Aprill, 2012. Kyiv, Ukraine. - P.110.

8. Moon F. C. Superconducting Levitation: Application to bearings and magnetic transportation, John Willey \& Sons, NY, 1994, 295p

9. Kozoriz V. Novel Magnetic Levitation and Propulsion Phenomena, ISBN 966-7108-10-4, Zaporizhya, 1999, 271p

10. J. M. Goodkind. The superconducting gravimeter. Rev. Sci. Instrum.-Vol. 70, № 11. - P. 4131-4152, 1999.

11. J. M. Goodkind and R. J. Warburton, IEEE Trans. Magn. MAG - 11, № 2, 1975.

1. Yatsenko V.A., Nalivaichuk N.V. Mathematical modeling and optimization of controlled superconducting sensors with magnetic levitation // Моделювання та дослідження стійкості динамічних систем: Збірник наукових праць міжнародна конференції DSMSI-2011. Київ, 2011. С. 146.

2. Yatsenko V.A. and Kryuchkov E.I. On the possibility of application of "Magnetic Potential Well" effect for creation of a graviinertial cryogenic device. Journal of Automation and Information Science, V. 34, 2003.-P. 106-119.

3. W.A. Prothero and J. M. Goodkind. A superconducting gravimeter. - Rev. Sci. Instr, № 2 , Vol. 39, № 9. 1968.- P. 1257 1261.

4. V.Yatsenko and P.Pardallos, Global optimization of cryogenic-optical sensor, in Sensors, Systems, and Next-Generation Satellites, K. W.H. Fujisada, J. Lirie, ed., Proc. SPIE 4550, гг. 433 - 441, 2001.

5. V. Yatsenko, M. Nalyvaichuk. Modeling and Optimization of Cryogenic-Optical Gravimeters // International Journal information theories \& applications. - 2012. - P. 232-240. Vol. 19. № 3.

6. V. Yatsenko, M. Nalyvaichuk. Cryogenic-Optical Gravimeter: Principles, Methods and Applications // Kharkov University Vestnik, Ser. Radiophysics and Electronics.-2011.- P. 107-113.

7. V. Yatsenko, M. Nalyvaichuk, V. Gnidenko, O. Kochkodan. Modeling of Superconducting Gravimeter for Futute Space Missions: Optimization. Control, and Estimation//2nd International Conference on memory of corresponding member of National Academy of Science of Ukraine V. S. Melnik, 4-6 Aprill, 2012. Kyiv, Ukraine. - P.110.

8. Moon F. C. Superconducting Levitation: Application to bearings and magnetic transportation, John Willey \& Sons, NY, 1994, 295p

9. Kozoriz V. Novel Magnetic Levitation and Propulsion Phenomena, ISBN 966-7108-10-4, Zaporizhya, 1999, 271p

10. J. M. Goodkind. The superconducting gravimeter. Rev. Sci. Instrum.-Vol. 70, № 11. - P. 4131-4152, 1999.

11. J. M. Goodkind and R. J. Warburton, IEEE Trans. Magn. MAG - 11, № 2, 1975. 